\title{
INVESTIGATION OF FRUCTANS INCREASING POSSIBILITIES IN RYE BREAD
}

\author{
Martins Sabovics $^{1 *}$, Liene Gudreniece ${ }^{1,2}$, Tatjana Kince ${ }^{1}$, Pavels Semjonovs ${ }^{3}$ \\ $I^{*}$ Department of Food Technology, Faculty of Food Technology, Latvia University of Agriculture, Rigas iela 22, Jelgava, \\ LV 3004, Latvia, e-mail: martins.sabovics@llu.lv \\ 2 Joint-stock company "Hanzas maiznica", Pildas iela 10, Riga, LV 1035, Latvia \\ ${ }^{3}$ Institute of Microbiology and Biotechnology, University of Latvia, Jelgavas iela 1, Riga, LV 1004, Latvia
}

\begin{abstract}
Nowadays, consumer's great attention is drawn to food with high nutritional value and its functional significance, and as we know the bread is one of the products consumed in the diet. The regular intake of prebiotics such as fructans, improves a few physiological features of human. Fructans concentration in rye flour is not sufficient to have a functional value for bread, but it is possible to add raw materials that contain a high fructans concentration in bread production process. Therefore, the aim of the research was to evaluate and increase the fructans content in rye bread using Jerusalem artichoke, chicory powder and sourdough with Gluconobacter nephelii acetic acid bacterium. During the research it was found that using Gluconobacter nephelii acetic acid bacterium, Jerusalem artichoke and chicory powder it is possible to increase the amount of fructans in rye bread. Obtained new rye bread samples have the same energy value as rye bread samples from Latvia market. But for functional products obtaining $12 \%$ Jerusalem artichoke powder and $9 \%$ chicory powder could be used in rye bread prescription, as a result the amount of fructans per $100 \mathrm{~g}$ of product could be $5 \mathrm{~g}$. Sourdough is the appropriate substrate to improve the use of bacterium (Gluconobacter nephelii) for increasing the content of fructans in the bread. Obtained products were not only with elevated nutritive value, it also has an appealing look, good texture, aroma and taste, customers like it and it is considered as a potentially functional product in the future.
\end{abstract}

Keywords: rye, fructans, Gluconobacter nephelii, Jerusalem artichoke, chicory.

\section{Introduction}

Nowadays, consumers pay more attention to products purchased on a daily basis and their most attention is focused on food with high nutritional value and its functional properties. The functionality in food mainly can be given by fructans which come from cereals and other products. Fructans are carbohydrates that consist mainly or exclusively of fructose and contain no or one glucose unit (Lewis, 1993). Fructans set an example of functional ingredients: also known as non-conventional sugars due to their prebiotic properties; make up a good opportunity to add value to the product either in terms of functionality or in profitability for the food industry. The regular intake of prebiotics such as fructooligosaccharides (FOS) and inulin improve a few physiological features, enhancing resistance against intestinal as well as extra-intestinal pathogens and promoting good immune response development, including the decrease of allergies (Roberfroid et al., 2010). As we know cereals are basic, popular and healthy raw materials, providing excellent opportunities for nutrition, health, diversity and innovation (Collar, 2015). The rye (Secale cereale L.) is the second most used grain for bread making, is likely to gain interest and popularity after wheat (Bushuk, 2001). In scientific literature data is available that the fructans concentration in rye is between 3.6 and $6.6 \%$ on dry matter basis. The fructans concentration in rye can be influenced by several factors as variety, growing and harvesting conditions, fertilizers and soil composition (Andersson et al., 2009). However, it is not possible to provide fructans concentration in rye bread in same amount as in grains mainly because of fructans thermal volatility. Nowadays there are some opportunities to increase the amount of fructans in rye bread. One of them is fructans production during sourdough making using Gluconobacter nephelii acetic acid bacteria. It has been shown that these bacteria in established substrate and in favourable growing conditions are producing fructans (Semjonovs et al., 2015). For a long time sourdoughs have been used for the leavening of the dough's as well as for the acid and flavour formations in wheat and rye dough's (Arendt et al., 2007). They are a mixture of flour and water fermented by lactic acid bacteria (LAB) and yeasts in a complex ecosystem, resulting in several biochemical processes such as acidification, proteolysis, synthesis of enzymes, antifungal compounds (Lavermicocca et al., 2000) as well as exopolysaccharides (EPS) (Tieking et al., 2003). Some other researchers have recently screened and identified other several strains of acetic acid bacteria (AAB) for/as being able to produce high amounts of polysaccharide from sucrose (Kowalsky et al., 2011; Semjonovs et al., 2017). Another option is to add additional raw materials, which composed a high fructans concentration, such as Jerusalem artichoke and chicory powder with high FOS content. The Jerusalem artichoke is widely known product in the world and the powder is obtained by drying and grinding of Jerusalem artichoke tubers. Jerusalem artichoke powder contain high amount of dietary fibre as - non-starch dietary fibre $-14 \%$, and inulin $-59 \%$, also minerals, and vitamins, it not contain bitter taste, but has pleasant, slightly sweet taste (Bekers et al., 2007; Gedrovica, 2012). The chicory (Cichorium intybus) belongs to the family Asteraceae having six species which may categorize on the basis of their geographical location in Europe or Asia. Most of the part of these plants possess a great medicinal importance due to the presence of various types of important compounds such as fructans, where its concentration in root is from

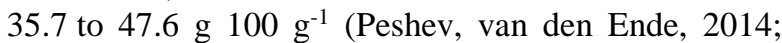
Abbas et al., 2015). Wherewith, developing recipes and 
technology, it is possible to obtain rye bread with higher fructans concentrations what we cannot purchase in Latvian markets. Therefore, the aim of the research was to evaluate and increase the fructans content in rye bread using Jerusalem artichoke, chicory powder and sourdough with Gluconobacter nephelii acetic acid bacterium.

\section{Materials and Methods}

Analyses were carried out at the Department of Food Technology in the Latvia University of Agriculture in Year 2016, but bread preparation was performed in the bakery company.

\section{Materials}

All used raw materials for the current study were purchased from wholesale trade companies in Europe.

Preparation of the recipe

Recipe was calculated per $100 \mathrm{~kg}$ cereal products including whole grain rye flour, wheat flour, nonfermented rye malt, rye flour, sugar, salt, yeast, caraway, malt and water.

\section{Sourdough preparation}

Two types of sourdough were prepared - one (as control) with $L b$. fructivorans and $C$. milleri bacteria, but second for fructans formation by two phases with lactic (L. reuteris 20016) and acetic acid (Gluconobacter nephelii) bacteria`s.

The control sourdough (used for bread control and bread samples with Jerusalem artichoke powder and chicory powder) was prepared by mixing rye flour with water and added bacteria mixture (industrial technology). Fermentation time and temperature for control sourdough were $24 \mathrm{~h}$ and $32{ }^{\circ} \mathrm{C}$. But sourdough for fructans production was prepared by two phase's method where rye flour and water was divided in two parts. In the first part half of rye flour, water and sugar were mixed together with bacteria mixture, and placed for fermentation $24 \mathrm{~h}$ at $28{ }^{\circ} \mathrm{C}$, after the first fermentation stage second half of flour, water and sugar was added to fermented mass and fermented again for $24 \mathrm{~h}$ at $32{ }^{\circ} \mathrm{C}$.

\section{Dough and bread preparation}

Eight dough samples were prepared with control sourdough in the present research, three samples with 4, 8 and $12 \%$ Jerusalem artichoke powder and control sourdough; three samples with 3, 6 and $9 \%$ chicory powder and control sourdough, and one sample with sourdough which was made with Gluconobacter nephelii acetic acid bacteria.

All ingredients were mixed in a spiral mixer (Wendel Diosna WV 400A) for $8 \pm 1 \mathrm{~min}$ at low speed (100 rpm). The initial temperature of dough was $32 \pm 2{ }^{\circ} \mathrm{C}$, dough moisture $43 \pm 1 \%$. Pre-fermentation time was 2 h $30 \mathrm{~min}$. After pre-fermentation dough was divided in $790 \mathrm{~g}$ pieces and formed. After placing dough in forms, it was proofed in fermentation chamber for $50 \pm 2 \mathrm{~min}$ in $36 \pm 2{ }^{\circ} \mathrm{C}$ with relative air humidity $75 \pm 5 \%$. Dough samples were baked in tunnel-type oven in 5 zones: $1^{\text {st }}$ zone baking temperature $260 \pm 10{ }^{\circ} \mathrm{C}$, steam $0.05 \mathrm{Bar} ; 2^{\text {nd }}$ zone $-240 \pm 10{ }^{\circ} \mathrm{C} ; 3^{\text {rd }}$ zone $-210 \pm 10{ }^{\circ} \mathrm{C} ; 4^{\text {th }}$ and $5^{\text {th }}$ zones $-190 \pm 10{ }^{\circ} \mathrm{C}$. Total baking time was $52 \pm 2 \mathrm{~min}$. Baked bread was cooled in a spiral cooler for $3 \mathrm{~h}$. The dough fermentation and baking time were the same for all dough samples.

\section{Determination of sourdough and bread quality}

The following parameters were analysed in obtained prepared sourdough and bread samples and in bread samples purchased from local markets:

1) Moisture content of bread was determined using air-oven method (AACC method 44-15.02).

2) Acidity of sourdough and bread was determined using AACC 02-31.01 method.

3) Fructans content in rye flour, sourdough and bread was determined using AACC 32.32 method.

\section{Sensory evaluation}

The ranking test (ISO 8587:2006) to rank samples according to their degree of liking and line scale method, based on the ISO 4121:2003 Sensory analysis Guidelines for the use of quantitative response scales was used for this study. In line scale method the samples were evaluated for flavour, aroma, acidity, structure, porosity and colour. Using ranking test the bread samples were evaluated sensory by 55 untrained panellists, but line scale method was done by 16 trained panellists.

\section{Statistical analysis}

The results (mean, standard deviation, p value) were processed using mathematical and statistical methods. Data were subjected to one-way analysis of variance (ANOVA) by Microsoft Office Excel 2013 and XLSTAT program; significance was defined at $\mathrm{p}<0.05$.

\section{Results and Discussion}

Determination of optimal Jerusalem artichoke and chicory powder ration in bread

In the first step of experimental study six new products were developed - rye bread with $4 \%, 8 \%, 12 \%$ Jerusalem artichoke powder, 3\%, 6\%, 9\% chicory powder. This experiment was done to understand the optimal amount of Jerusalem artichoke and chicory powder in rye bread composition in order to get functional characteristics and not reducing product quality - particularly the appearance and taste. After sensory evaluation of obtained bread samples taste differences, it was determined that, there is no significant difference $(\mathrm{p}>0.05)$ comparing with control sample. Therefore, the added amount of powders does not significantly affect the taste of rye bread. The highest fructans concentration was detected in rye bread with

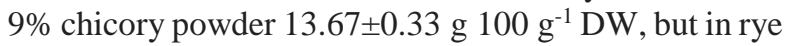
bread with $12 \%$ Jerusalem artichoke powder the

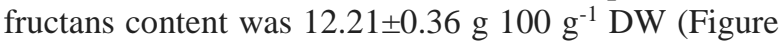
$1)$. In control sample the fructans concentration was 12fold and 13-fold less, comparing with bread samples with added powders. However, fructans concentration

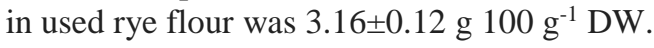

The fructans concentration does not increase in proportion to the quantity of added powders amount, 
because it depends on fermentation time, baking conditions and yeast activity (JasińskaKuligowska et al., 2013; Verspreet et al., 2013).

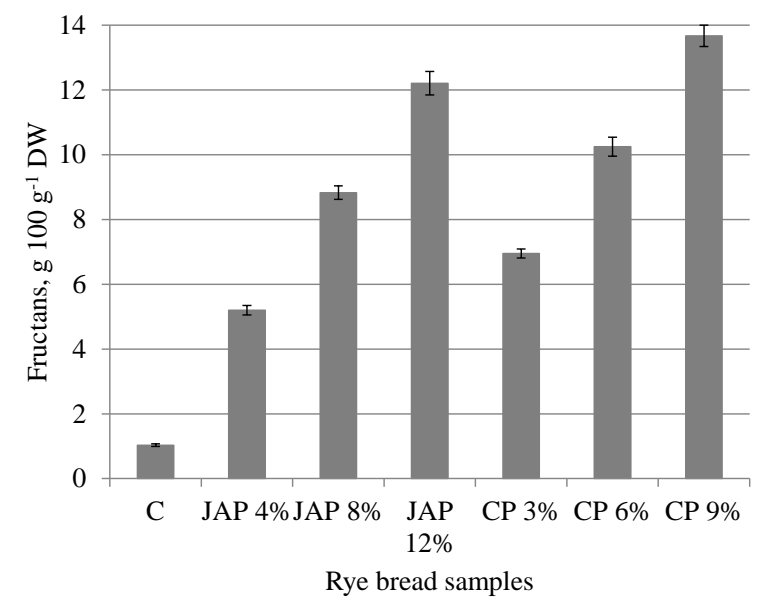

Figure 1. Fructans amount in new developed products, g $100 \mathrm{~g}^{-1} \mathrm{DW}$

C - control,

JAP - rye bread with Jerusalem artichoke powder,

$\mathrm{CP}$ - rye bread with chicory powder

In the scientific literature is mentioned, the minimum amount of fructans at which they have a positive impact on favourable growth for bacteria in humans should be 5-8 g per day (Kolida, Gibson, 2007; Ramnanil et al., 2014). Therefore, for further experiments rye bread samples with $12 \%$ Jerusalem artichoke and $9 \%$ chicory powder were used.

Fructans content evaluation in sourdough

The differences of microflora what can be used for sourdough production give diversified taste, aroma, acidity and consistency (Demarigny, Gerber, 2014) of final product. Control sourdough was used for control rye bread and for bread samples with Jerusalem artichoke and chicory powder, but the newly developed sourdough with acetic acid (Gluconobacter nephelii) bacteria was used for rye bread to increase fructans content. Sourdough acidity was measured every $4 \mathrm{~h}$ (Figure 2) to get the sourdough with acceptable properties which should be suitable for rye bread production.

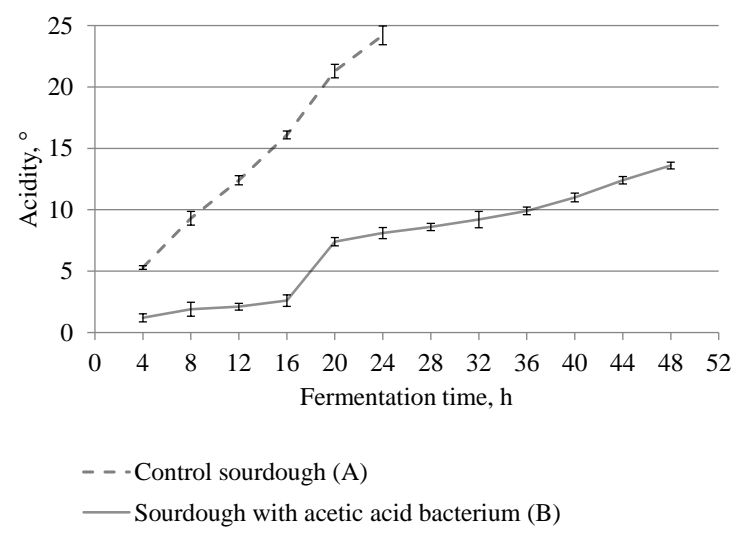

Figure 2. Sourdough acidity $\left(^{\circ}\right)$ changes during fermentation
It can be seen in Figure 2, the sourdough (A) acidification increasing tendency is very rapid and after $24 \mathrm{~h}$ of fermentation the sourdough has reached the necessary acidity $-24.2 \pm 0.76^{\circ}$.

The acidity increase in sourdough (B) was not so rapid, therefore the fermentation time is two times longer and after $48 \mathrm{~h}$ of fermentation the acidity increases $\left(13.6 \pm 0.27^{\circ}\right)$, comparing with sourdough $(\mathrm{A})$. The most rapid increase of acidity in sourdough (B) was observed during fermentation from 16 to 20 hours, depending on bacteria adaptation to the environment, optimal temperature and nutrients.

To provide the necessary acidity of dough after $2.5 \mathrm{~h}$ of fermentation, the sourdough to the dough was added two times more, not exchanging other raw material amounts. Before and after the fermentation the fructans content in sourdough was determined (Figure 3). According to the results using acetic acid (Gluconobacter nephelii) bacteria and lactic acid (L. Reuter 20016) bacteria, it is possible to increase the fructans concentration in sourdough.

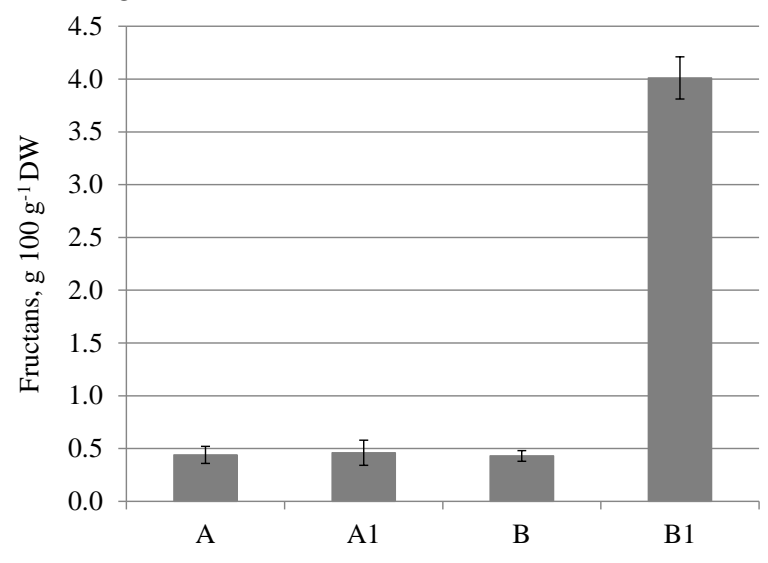

Figure 3. Fructans content in sourdough samples before and after fermentation, $\mathrm{g} 100 \mathrm{~g}^{-1} \mathrm{DW}$

A - control sourdough before fermentation

A1 - control sourdough after fermentation

B - sourdough with acetic acid bacteria before fermentation B1 - sourdough with acetic acid bacteria after fermentation

Fructans content in sourdough (B) after fermentation

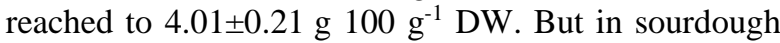
(A) fructans content did not change.

In addition to the nutrients in the flour, sucrose was added to sourdough, because it is required for the synthesis of fructans and the disaccharide concentration is one of the main preconditions for fructans synthesis (Pollock et al., 2003).

Rye bread moisture, acidity, fructans content and sensory evaluation

Rye bread technological process takes many hours, including sourdough, dough preparation, fermentation, and baking. In order to check out fructans formation process in rye bread, for the control sample there was not used raw materials, which are composed of a high (>20 g to $100 \mathrm{~g}^{-1} \mathrm{DW}$ ) fructans content. The analyses and sensory evaluation were done for three new products obtaining in comparison with control sample (Table 1). 


\section{Table 1}

Physically-chemical parameters of rye bread

\begin{tabular}{|c|c|c|c|c|}
\hline \multirow{2}{*}{ Parameters } & \multirow{2}{*}{$\begin{array}{l}\text { Control } \\
\text { sample }\end{array}$} & \multicolumn{3}{|c|}{ Rye bread samples } \\
\hline & & JAP & $\mathbf{C P}$ & SAA \\
\hline Moisture, \% & 44.68 & 46.21 & 45.83 & 44.93 \\
\hline Acidity, ${ }^{\circ}$ & 9.23 & 9.11 & 8.75 & 8.45 \\
\hline $\begin{array}{l}\text { Fructans, } \\
\text { g } 100 \mathrm{~g}^{-1}\end{array}$ & 0.46 & 5.63 & 6.06 & 2.10 \\
\hline
\end{tabular}

JAP - rye bread with $12 \%$ Jerusalem artichoke powder $\mathrm{CP}$ - rye bread with $9 \%$ chicory powder

SAA - rye bread with added sourdough with acetic acid bacteria

Results of present experiments demonstrate that new developed products have higher moisture content compared to the control sample, mainly because Jerusalem artichoke and chicory powders has lower water-binding capacity than flour, due to the fact that these raw materials contain high concentration of fructooligosaccharides. Adding to the recipes raw materials containing fructooligosaccharides, dough water absorption capacity decreases, because fructooligosaccharides create a barrier around the starch molecules, which restrict the water binding capacity (Karolini-Skaradzinska et al., 2009), therefore after baking moisture content of obtained bread samples was higher.

The lowest $\left(8.45 \pm 0.09^{\circ}\right)$ acidity was detected in the rye bread sample SAA, but acidity of control sample was the highest $-9.23 \pm 0.11^{\circ}$. Traditionally, sourdough quality depends on the incorporated microflora, resulting increase of dough acidity, which was slower compared to dough with control sourdough (A1). It should be noted that the required fermentation time $(2.5 \mathrm{~h})$ was sufficient to implement the technological process and provide final product quality. Statistically significant $(p<0.05)$ changes were detected for fructans content in obtained bread samples. Higher fructans content was obtained in rye bread with $9 \%$ chicory powder and $12 \%$ Jerusalem artichoke powder (Table 1). In the control sample fructans content was $0.46 \pm 0.04 \mathrm{~g} 100 \mathrm{~g}^{-1}-$ by $92 \%$ less than in rye bread with $9 \%$ chicory powder. It is necessary to indicate, that fructans concentration in bread could be affected not only by $\mathrm{pH}$ or acidity, but of increased processing temperature too, as higher than $90{ }^{\circ} \mathrm{C}$ (Matusek et al., 2009).

However, essential difference in fructans concentration in commercial rye bread samples purchased in Latvian markets was found (Figure 4). Commercial rye bread has comparably low fructans concentration, which can be mainly based on used flour and other cereal products which are included in the recipes.

Appraising the results, it is evident that the newly developed rye bread samples have higher fructans content (Table 1) in comparison with commercial rye bread samples (Figure 4).

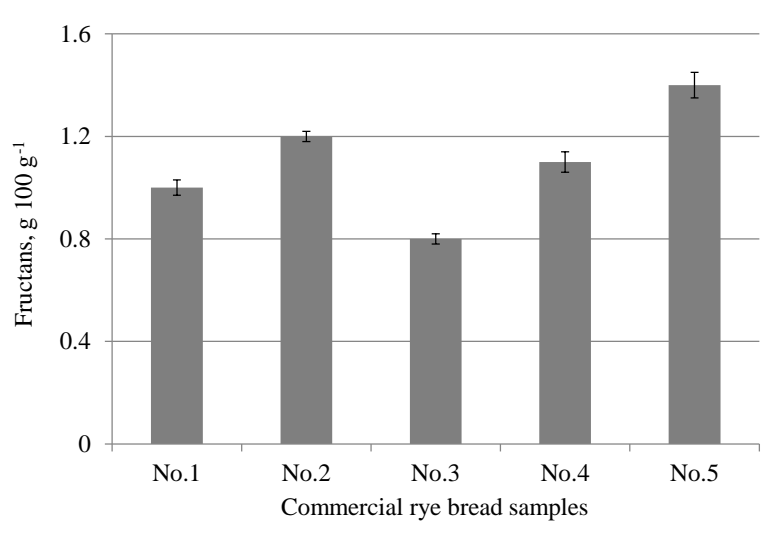

Figure 4. Fructans content in commercial rye bread samples

Sensory properties of new products mainly could provide offering to consumers. Results of sensory evaluation demonstrate that sensory properties of developed rye bread samples were significantly different in comparison with the control sample.

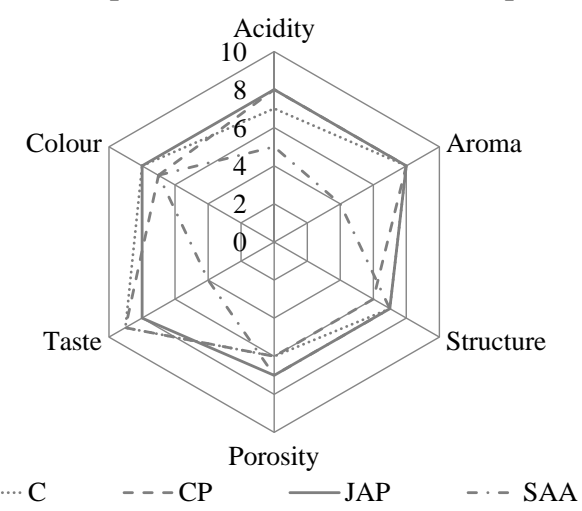

Figure 5. Sensory properties star diagram

$\mathrm{C}$ - control sample

JAP - rye bread with $12 \%$ Jerusalem artichoke powder $\mathrm{CP}$ - rye bread with $9 \%$ chicory powder

SAA - rye bread with added sourdough with acetic acid bacteria

Fundamental difference was obtained in taste and aroma, which was described as a specific, unusual for sample SAA and all experts felt bitter aftertaste. Other parameters as acidity, structure, porosity and colour didn't differ significantly $(\mathrm{p}<0.05)$, comparing to other samples and control. The experts noted, that the samples are qualitative and don't require significant changes.

The degree of liking of rye bread was done by 55 untrained persons (consumers) and in summarized data (Figure 6) can be seen, that they really liked the sample with $9 \%$ chicory powder which they described with a intrinsic aroma and sweet aftertaste. Consumers dislike a rye bread with acetic acid bacteria, because it gives lasting bitter aftertaste and some consumers didn't like the flavour. Significant difference of rye bread samples liking were detected. ANOVA results showed that the sample $(\mathrm{CP} 9 \%)$ with $\mathrm{F}_{\text {cal }}=45.45$ and the sample $(\mathrm{SAA})$ with $\mathrm{F}_{\text {cal }}=10.44$ are higher than $\mathrm{F}_{\text {crit }}=3.93$ $\left(\mathrm{n}_{1}=3, \mathrm{n}_{2}=216, \alpha=0.05\right)$, therefore for those samples 
there are significant difference in degree of liking, comparing with control sample.

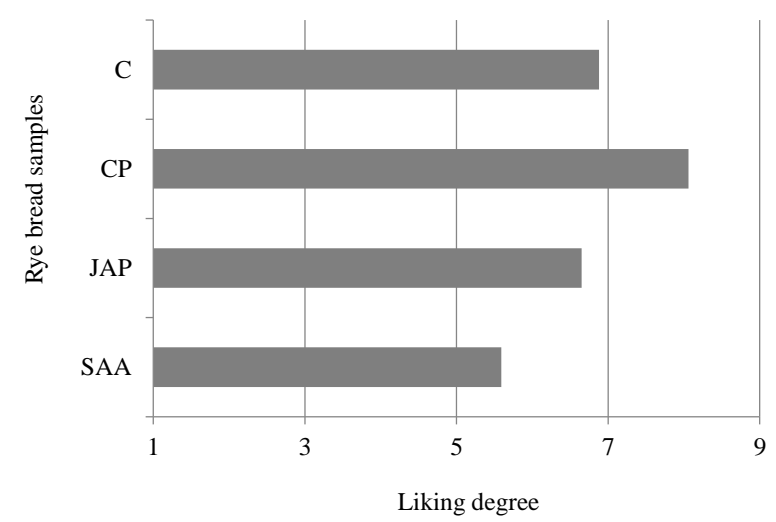

Figure 6. Hedonic evaluations of rye bread samples

C - control sample

JAP - rye bread with $12 \%$ Jerusalem artichoke powder $\mathrm{CP}$ - rye bread with $9 \%$ chicory powder

SAA - rye bread with added sourdough with acetic acid bacteria

But in comparison with control sample and the rye bread with added 12\% Jerusalem artichoke powder, doesn't have differences in degree of liking, because $F_{c a l}=3.17$. But it should be noted that fructans concentration in products should not exceed $20 \mathrm{~g}$ per $100 \mathrm{~g}^{-1}$ dry matter. High intake of fructans can contribute to abdominal discomfort, flatulence but higher than $30 \mathrm{~g}$ per day can cause diarrhoea and vomiting (Den Hond et al., 2000).

\section{Conclusions}

Obtained rye bread with $9 \%$ chicory powder fructans

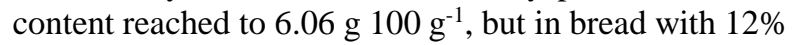
Jerusalem artichoke powder - $5.63 \mathrm{~g} 100 \mathrm{~g}^{-1}$; bread aroma and taste was not changed in comparison with traditional rye bread without additives. Using special microflora, like Gluconobacter nephelii acetic acid bacterium, it is possible to increase the fructans content in the final product. Fructans content in rye bread with developed sourdough (contain Gluconobacter nephelii) is higher compared to the control sample.

\section{Acknowledgment}

Research has been supported by the National research programme "Agricultural Resources for Sustainable Production of Qualitative and Healthy Foods in Latvia" (AgroBioRes) (2014 2017), project No. 4 "Sustainable use of local agricultural resources for qualitative and healthy food product development" (FOOD) in cooperation with joint-stock company "Hanzas maiznica”.

\section{References}

1. Abbas Z.K., Saggu S., Sakeran M.I., Zidan N., Rehman H., Ansari A.A. (2015) Phytochemical, antioxidant and mineral composition of hydroalcoholic extract of chicory (Cichorium intybus L.) leaves. Saudi Journal of Biological Sciences, Vol. 22, p. 322-326.

2. Andersson R., Fransson G., Tietjen M., Aman P. (2009) Content and molecular-weight distribution of dietary fiber components in whole-grain rye flour and bread. Journal of Agricultural and Food Chemistry, Vol. 57, p. 2004-2008.

3. Arendt E.K., Ryan L.A., Dal Bello F. (2007) Impact of sourdough on the texture of bread. Food Microbiology, Vol. 24, p. 165-174.

4. Bekers M., Grube M., Upite D., Kaminska E., Linde R., Scherbaka R., Danilevich A. (2007) Carbohydrates in Jerusalem artichoke powder suspension. Nutrition and Food Science, Vol. 37 (1), p. 42-49.

5. Bushuk W. (2001) Rye production and uses worldwide. Cereal Foods World, Vol. 46, p. 70-73.

6. Collar C. (2015) Role of bread on nutrition and health worldwide. In: Bread and its Fortification: Nutrition and health benefits. C.M. Rosell, J. Bajerska, A.F. El Sheikha (eds). CRC Press, p. 26-52.

7. Demarigny Y., Gerber P. (2014) Usefulness of Natural Starters in Food Industry: The Example of Cheeses and Bread. Food and Nutrition Sciences, Vol. 5, p. 1679-1691.

8. Den Hond E., Geypens B., Ghoos Y. (2000) Effect of high performance chicory inulin on constipation. Nutrition Research, Vol. 20, p. 731-736.

9. Gedrovica I. (2012) Pastry products enriched with dried Jerusalem artichoke (Helianthus tuberosus L.) powder: Promotion work. Jelgava: LLU, $156 \mathrm{p}$.

10. Jasińska-Kuligowska I., Kuligowski M., Kołodziejczyk P., Michniewicz J. (2013) Wpływprocesów fermentacji, ekstruzji iwypiekuna zawartość fruktanów w produktach żytnich (Effect of fermentation, extrusion and baking processes on content of fructans in rye products). $\dot{Z} y w n o s ́ c ́$. Nauka. Technologia. Jakość, Vol. 90, p. 129-141.

11. Karolini-Skaradzinska Z., Bihuniak P., Piotrowska E., Wdowik L. (2007) Properties of dough and qualitative characteristics of wheat bread with addition of inulin. Polish Journal of Food and Nutrition Sciences, Vol. 57, No. 4(B), p. 267-270.

12. Karppinen S., Myllymaki O., Forssell P., Poutanen K. (2003) Fructan content of rye and rye products. Cereal Chemistry, Vol. 80, p. 168-171.

13. Kolida S., Gibson G.R. (2007) Prebiotic Capacity of Inulin-Type Fructans. The Journal of Nutrition, Vol. 137(11), p. 2503-2506.

14. Kowalsky P., Blum W., Weber T. (2011) Produkt- und Marken differenzierung als Ausdruckeiner Unternehmensphilosophie. In: Markendifferenzierung: Innovative Konzeptezurerfolgreichen Markenprofilierung. F. Völckner, C. Willers, T. Weber (Eds.). GablerVerlag - Springer Fachmedien GmbH, Wiesbaden, p. 245-258.

15. Lavermicocca P., Valerio F., Evidente A., Lazzaroni S., Corsetti A., Gobbetti M. (2000) Purification and characterization of novel antifungal compounds from the sourdough Lactobacillus plantarum strain 21B. Applied and Environmental Microbiology, Vol. 66, p. 4084-4090.

16. Lewis D.H. (1993) Nomenclature and diagrammatic representation of oligomeric fructans - a paper for discussion. New Phytologist, Vol. 124, p. 583-594.

17. Matusek A., Meresz P., Diem-Le T. K., Orsi F. (2009) Effect of temperature and $\mathrm{pH}$ on the degradation of fructooligasaccharides. European Food Research Technology, Vol. 228, p. 355-365.

18. Peshev D., Van den Ende W. (2014) Fructans: prebiotics and immunomodulators. Journal of Functional Foods, Vol. 8, p. 384-357.

19. Pollock C, Farrar J, Tomos D, Gallagher J, Lu C, Koroleva O. (2003) Balancing supply and demand: the spatial regulation of carbon metabolism in grass and 
cereal leaves. Journal of Experimental Botany, Vol. 54, p. 489-494.

20. Ramnani P., Costabile1 A., Bustillo A.G.R., Gibson R. G. (2014) A randomised, double- blind, cross-over study investigating the prebiotic effect of agave fructans in healthy human subjects. Journal of nutritional science, Vol. 4, p. 1-10.

21. Roberfroid M., Gibson G. R., Hoyles L., McCartney A. L., Rastall R., Rowland I., et al. (2010) Prebiotic effects: metabolic and health benefits. British Journal of Nutrition, Vol. 104, p. 1-63.

22. Semjonovs P., Ruklisha M., Paegle L., Saka M., Treimane R., Skute M., Rozenberga L., Vikele L., Sabovics M., Cleenwerck I. (2017) Cellulose synthesis by Komagataei bacterrhaeticus strain P 1463 isolated from Kombucha. Applied Microbiology and Biotechnology. Vol. 101(3), p. 1003-1012.
23. Semjonovs P., Shakirova L., Treimane R., Shvirksts K., Auzina L., Cleenwerck I., Zikmanis P. (2015) Production of extracellular fructans by Gluconobacternephelii P1464. Letters in Applied Microbiology, Vol. 62(2), p. 145-152.

24. Tieking M., Korakli M., Ehrmann M.A., Ganzle M.G., Vogel R.F. (2003) In situ production of exopolysaccharides during sourdough fermentation by cereal and intestinal isolates of lactic acid bacteria. Applied and Environmental Microbiology, Vol. 69, p. 945-952.

25. Verspreet J., Hemdane S., Dornez E., Cuyvers S., Delcour J.A., Courtin C.M. (2013) Maximizing the concentrations of wheat grain fructans in bread by exploring strategies to prevent their yeast (Saccharomyces cerevisiae) - mediated degradation. Journal of Agricultural and Food Chemistry, Vol. 61, p. 1397-1404. 